The Egyptian Journal of Hospital Medicine (October 2020) Vol. 81 (2), Page 1438-1443

\title{
Subclinical Enthesitis in Rheumatoid Arthritis Patients and its Relation to Disease Parameters and Disease Activity
}

\author{
Mohamed Ismail Mohamed AbdelKareem, Tarek Mohamed AbdelAziz, Asmaa Abd ELraheem Borai* \\ Departement of Rheumatology, Physical Medicine \& Rehabilitation, \\ Faculty of Medicine - Al-Azhar University (Assiut) \\ *Corresponding author: Asmaa Abd ELraheem Borai, Mobile: (+20) 01014874897, E-Mail: Asmaa.123alborai@gmail.com
}

\begin{abstract}
Background: Rheumatoid Arthritis (RA) is a chronic systemic autoimmune disorder of unknown etiology characterized by symmetrical joint synovitis and pain. RA has a wide clinical spectrum and may vary from mild nonerosive disease to severe inflammation and joint damage with extra articular manifestations. To detect enthesopathy, the European League Against Rheumatism (EULAR) recommends magnetic resonance imaging (MRI) or ultrasonography (US).

Objective: To detect subclinical enthesitis in rheumatoid arthritis patients and its relation to disease parameters and disease activity. Patients and Methods: This prospective observational study included 50 adult patients diagnosed as rheumatoid arthritis according to the 2010 ACR-EULAR classification criteria for rheumatoid arthritis. The study was carried out in the Musculoskeletal Ultrasonography Unit of the Rheumatology, Physical Medicine and Rehabilitation Department, Al-Azhar University Hospitals Assiut.

Results: We found that the mean age in case group was $46.3 \pm 8.4$ years. Females accounted for $62 \%$ (31 patients) of all patients. The disease duration ranged from one year to 15 years with a mean of $6.2 \pm 1.9$ years. The BMI was 19.5 $\pm 42 \mathrm{~kg} / \mathrm{m}^{2}$. Mean of disease activity evaluated by the disease activity score in 28 joints was $4.7 \pm 1.5$. Our findings demonstrated that prevalence of subclinical enthesitis in patients with rheumatoid arthritis was $32 \%$. There was a statistically significant relation between 28-joint Disease Activity Score (DAS28) score and ultrasound detected enthesitis (p. value <0.05).
\end{abstract}

Conclusion: BMI, old age and long disease duration were suggested as the risk factors for subclinical enthesitis.

Keywords: Subclinical enthesitis, Rheumatoid Arthritis Patients, MRI, US, BMI.

\section{INTRODUCTION}

Rheumatoid arthritis (RA) is a chronic systemic autoimmune disorder of unknown etiology characterized by symmetrical joint synovitis and pain. RA has a wide clinical spectrum and may vary from mild non-erosive disease to severe inflammation and joint damage with extra-articular manifestations. The wrist and hand joints were affected early in the disease process, with some deformities occurring in the first two years of the disease ${ }^{(\mathbf{1})}$.

Rheumatoid arthritis is characterized by proliferative, hypervascularized synovitis, resulting in bone erosion, cartilage damage, joint destruction and long-term disability. The absence of effective treatment to prevent joint destruction has limited the need for more sensitive imaging techniques. Availability of these powerful and expensive drugs has created new demands on radiologists to identify patients with aggressive rheumatoid arthritis at an early stage to affect the therapeutic management of these patients ${ }^{(2)}$.

Enthesis is the zones where tendon, ligament, or joint capsule are attached at a bone to facilitate easy joint motion and assist in transmission of tensile load from soft tissues to bone ${ }^{(3)}$.

Enthesopathy is characterized by inflammation of insertions of tendons, ligaments or capsules into the bone. However, recognizing enthesopathy could be challenging because of low sensitivity and specific clinical testing. To detect enthesopathy, the European League against Rheumatism (EULAR) recommends magnetic resonance imaging (MRI) or ultrasonography (US) ${ }^{(4)}$.

MRI had excellent results in evaluation of early RA. MRI wrist demonstrated bone erosions, synovial hypertrophy, synovitis and tenosynovitis. Other signs include tendinitis, enthesitis, ligament and tendon tears, bone marrow edema and joint effusions ${ }^{(5)}$.

Ultrasonography is an imaging technique that has attracted much interest in the field of rheumatology in recent years. Because of technological improvements and wide availability, ultrasonography has the potential to facilitate diagnosis of RA and improve the assessment of disease activity ${ }^{(6)}$. Imaging studies are more sensitive and specific than clinical examination in the diagnosis of enthesitis, and even ultrasonography might be superior to MRI in detection of early signs of enthesopathy ${ }^{(7)}$. Ultrasonography (US) is the best tool to evaluate periarticular soft tissue as it is sufficient for discovering both early (edema and thickening) and late changes (erosion and enterophytosis). Further, it's a safe, and easily ready, inexpensive and reproducible manoeuvre ${ }^{(\boldsymbol{8})}$. 
The aim of this work was to detect subclinical enthesitis in rheumatoid arthritis patients and its relation to disease parameters and disease activity.

\section{PATIENTS AND METHODS}

This prospective observational study included 50 adult patients diagnosed as rheumatoid arthritis according to the 2010 ACR-EULAR classification criteria for rheumatoid arthritis ${ }^{(9)}$. The study was carried out in the Musculoskeletal Ultrasonography Unit of the Rheumatology, Physical Medicine and Rehabilitation Department, Al-Azhar University Hospitals Assiut. Systematic random sampling technique was used.

Inclusion criteria: Patients diagnosed as rheumatoid arthritis and age $>18$ years old.

Exclusion criteria: Presence of clinical enthesitis, other forms of connective tissue diseases or microcrystalline arthritis, patients with other autoimmune diseases as systemic lupus erythematous (SLE), type $1 \mathrm{DM}$, autoimmune thyroid disease and Addison's disease (AD). Patients who had traumatic, septic, or previous joint or entheseal surgery, patients with chronic hepatitis C or B viral infection, patients with endocrinal disease, patients with other systemic diseases, patients who are $<18$ years old, pregnant female, and non-compliant patients.

\section{All patients were subjected to the following: \\ I- History and Clinical Examination:}

- Personal History.

- History of present illness: Analysis of the following complaints of joint symptoms: Pain (inflammatory or mechanical), stiffness, swelling, weakness, fatigue, distribution, history of other systems affection and history of other comorbid conditions such as DM, cardiac disease and renal failure

- Past history: Childhood arthritis or connective tissue diseases, history of medication, surgical operations, allergy and blood transfusion had to be checked out.

- Family history: Similar conditions and rheumatic illness.

II- Full Clinical Examination:

- General examination: General condition, vital signs. Anthropometric measures were assessed, which include height, weight and BMI.

- Examination of the enthesis: Inferior and superior pole of the calcaneus, inferior and superior pole of the patella and tibial and olecranon tuberosity were examined. The presence of clinical enthesitis was defined as tenderness on firm palpation and soft tissue swelling at the insertion of the tendon.

- Locomotor examination inspection: Swelling, deformity, muscle wasting. Palpation for hotness, tenderness and crepitus. Range of active and passive movement of the following joints: shoulder, elbow, wrist, metacarpophalyngeal joints (MCP), proximal interphalyngeal joints (PIP), distal interphalyngeal (DIP) of fingers, hip, knee, ankle, midtarsal (MT), metatarsophalyngeal (MTP), proximal interphalyngeal (PIP), distal interphalyngeal (DIP) of toes and subtalar joint (ST).

- Disease activity assessment: Disease activity was assessed by calculating the 28-joint Disease Activity Score (DAS28/ESR).

II- Laboratory Investigations: Complete blood picture, liver function profile and erythrocyte sidemintation rate (ESR) was performed by the Westergren method, latex agglutination slide test was performed for qualitative and semiquantitative determination of $\mathrm{C}$-reactive protein in nondiluted serum and rheumatoid factor was determined by the latex fixation test.

III- Imaging study: Studied patients were submitted to screening with the following procedures:

- Plain radiography was performed for both hands and feet (P/A view). Radiological evaluation included analysis of the following: Presence of erosions, joint space narrowing or ankyloses and subluxation and /or dislocation.

- Musculoskeletal ultrasonography: Conventional grey scale ultrasound and power Doppler examinations were carried out using (Toshiba Xario200), with a linear $10-12 \mathrm{MHz}$ probe. Contact gel was applied to the skin to provide an acoustic interface.

Ethical approval and written informed consent: This trial was approved by Committee of Rheumatology, Physical Medicine and Rehabilitation Department and Committee of Faculty of Medicine at Al-Azhar University and then, by the Ethical Committee of Al-Azhar University. All subjects involved in the current study were informed about the nature and details of the current work and a written consent was obtained for each participant. All the gathered data were treated confidentially and were used for research purpose only.

\section{Statistical analysis}

Data were analyzed using Statistical Program for Social Science (SPSS) version 18.0. Quantitative data were expressed as mean \pm standard deviation (SD). Qualitative data were expressed as frequency and percentage. Chi-square $\left(\mathrm{X}^{2}\right)$ test of significance was used in order to compare proportions between two qualitative parameters. Pearson's correlation coefficients (r) were calculated for detection of parametric correlations. Spearman's correlation coefficients ( $r$ ) were calculated for detection of nonparametric correlations between variables in one group. $\mathrm{P}$-value $\leq 0.05$ was considered significant. $\mathrm{P}$ value $<0.001$ was considered as highly significant. $\mathrm{P}$ value $>0.05$ was considered insignificant. 
RESULTS

Table (1): Age and sex distribution of the studied patients

\begin{tabular}{|l|c|c|}
\hline & No. $(\mathbf{n = 5 0})$ & \% \\
\hline Age: & \multicolumn{2}{|c|}{} \\
$<25$ years & 12 & $24 \%$ \\
$25-<30$ years & 14 & $28 \%$ \\
$30-<35$ years & 12 & $24 \%$ \\
$\geq 35$ years & 12 & $24 \%$ \\
Mean \pm SD & \multicolumn{2}{|c|}{$46.3 \pm 8.4$} \\
\hline Gender: & 19 & $38 \%$ \\
Male & 31 & $62 \%$ \\
Female & $65 \%$ \\
\hline
\end{tabular}

Age ranged from 20 to 65 years with mean age of $46.3 \pm 8.4$ years. The highest percentage of the patients was at the age $\geq 35$ years. The lowest percentage of the patients was at the age $<25$ years, with mean age of $35.8 \pm 10.6$ years. There were 19 males $(38 \%)$ and 31 females $(62 \%)$ in the studied patients.

Table (2): Description of disease duration, BMI, ESR, CRP, rheumatoid factor, hand X-ray and ultrasound findings in studied patients

\begin{tabular}{|c|c|c|}
\hline & No. $(n=50)$ & $\%$ \\
\hline $\begin{array}{l}\text { Disease duration (years): } \\
<5 \text { years } \\
5-<10 \text { years } \\
\geq 10 \text { years } \\
\text { Mean } \pm S D\end{array}$ & $\begin{array}{l}13 \\
17 \\
20 \\
\quad 6.2 \pm\end{array}$ & $\begin{array}{r}26 \% \\
34 \% \\
40 \% \\
9\end{array}$ \\
\hline $\begin{array}{l}\text { BMI }\left(\mathbf{k g} / \mathbf{m}^{2}\right): \\
\text { Normal weight }(18.5-24.9) \\
\text { Over weight }(25-29.9) \\
\text { Obesity }(>30) \\
\text { Mean } \pm \text { SD }\end{array}$ & $\begin{array}{l}10 \\
18 \\
22 \\
(19.5 \pm\end{array}$ & $\begin{array}{r}20 \% \\
36 \% \\
44 \% \\
42)\end{array}$ \\
\hline $\begin{array}{l}\text { Disease severity (DAS): } \\
\text { Remission }(<2.6) \\
\text { Mild }(2.6-<3.2) \\
\text { Moderate }(3.2-5.1) \\
\text { Sever }(>5.1)\end{array}$ & $\begin{array}{c}13 \\
8 \\
8 \\
21\end{array}$ & $\begin{array}{l}26 \% \\
16 \% \\
16 \% \\
42 \%\end{array}$ \\
\hline $\begin{array}{l}\text { ESR: } \\
\text { Normal } \\
\text { Elevated }\end{array}$ & $\begin{array}{l}10 \\
40\end{array}$ & $\begin{array}{l}20 \% \\
80 \%\end{array}$ \\
\hline $\begin{array}{l}\text { CRP: } \\
\text { Negative } \\
\text { Positive }\end{array}$ & $\begin{array}{l}20 \\
30\end{array}$ & $\begin{array}{l}40 \% \\
60 \%\end{array}$ \\
\hline $\begin{array}{l}\text { Rheumatoid factor: } \\
\text { Negative } \\
\text { Positive }\end{array}$ & $\begin{array}{c}4 \\
46 \\
\end{array}$ & $\begin{array}{c}8 \% \\
92 \% \\
\end{array}$ \\
\hline $\begin{array}{l}\text { Hand X-ray: } \\
\text { Normal } \\
\text { Abnormal } \\
\text { Bone deformity } \\
\text { Bone erosion } \\
\text { Sub-chondralcyct } \\
\text { Peri-articular osteopenia }\end{array}$ & $\begin{array}{c}6 \\
44 \\
6 \\
12 \\
12 \\
14\end{array}$ & $\begin{array}{l}12 \% \\
88 \% \\
13.6 \% \\
27.3 \% \\
27.3 \% \\
31.8 \%\end{array}$ \\
\hline $\begin{array}{l}\text { US: } \\
\text { Normal } \\
\text { Abnormal } \\
\end{array}$ & $\begin{array}{l}34 \\
16 \\
\end{array}$ & $\begin{array}{l}68 \% \\
32 \% \\
\end{array}$ \\
\hline
\end{tabular}

Table (2) showed that $26 \%$ of patients had disease duration $<5$ years, 34\% of patients had disease duration of 5-10 years and $40 \%$ of patients had disease duration of 10 years.

- $20 \%$ of patients had BMI of 18.5-24.9, 36\% of patients had BMI of 25-29.9 and 44\% of patients had BMI $>30$. The all-mean BMI was $19.5 \pm 42$.

- $26 \%$ of patients had DAS score of $<2.6,16 \%$ of patients had DAS score of $2.6-3.2,16 \%$ of patients had DAS score of $3.2-5.1$ and $42 \%$ of patients had DAS score of $>5.1$.

- About $80 \%$ of patients have elevated ESR $>20$ $\mathrm{mm} / \mathrm{h}$ and about $20 \%$ of patients have normal ERS.

- About $40 \%$ of patients have negative CR.P and about $60 \%$ of patients have positive C.R.P.

- About $8 \%$ of patients have negative rheumatoid factor and about $92 \%$ of patients have positive rheumatoid factor.

- About $12 \%$ of patients have normal hand X-ray and About $88 \% \%$ of patients have abnormal hand X-ray. $13.6 \%$ of patients showed bone deformity, $27.3 \%$ of patients had bone erosion, $27.3 \%$ of patients had sub-chondral cyst and $31.8 \%$ of patients had peri-articular osteopenia.

- About $68 \%$ of patients have normal ultrasound findings and about $32 \%$ of patients have abnormal ultrasound findings.

Table (3): Ultrasound abnormalities of in the abnormal group

\begin{tabular}{|l|c|c|}
\hline & No. $(\mathbf{n}=\mathbf{1 6})$ & $\%$ \\
\hline $\begin{array}{l}\text { Quadriceps } \\
\text { enthesis }\end{array}$ & 3 & $18.8 \%$ \\
\hline $\begin{array}{l}\text { Proximal patellar } \\
\text { enthesis }\end{array}$ & 3 & $18.8 \%$ \\
\hline $\begin{array}{l}\text { Distal patellar } \\
\text { enthesis }\end{array}$ & 3 & $18.8 \%$ \\
\hline Achilles enthesis & 5 & $31.3 \%$ \\
\hline $\begin{array}{l}\text { Plantar } \\
\text { aponeurosisenthesis }\end{array}$ & 2 & $12.5 \%$ \\
\hline
\end{tabular}

Table (3) showed that there were 3 patients (18.8\%) with quadriceps enthesis, 3 patients $(18.8 \%)$ with proximal patellar enthesis, 3 patients $(18.8 \%)$ with distal patellar enthesis, 5 patients $(31.3 \%)$ with achilles enthesis \& 2 patients (12.5\%) with Plantar aponeurosisenthesis. 
Table (4): Relation between ultrasound findings and age, sex, disease duration, disease severity (DAS28), BMI and hand X-ray.

\begin{tabular}{|c|c|c|c|c|c|}
\hline & \multicolumn{4}{|c|}{ Ultrasound findings } & \multirow{3}{*}{ P-value } \\
\hline & \multicolumn{2}{|c|}{ Normal $(n=34)$} & \multicolumn{2}{|c|}{ Abnormal $(n=16)$} & \\
\hline & No. & $\%$ & No. & $\%$ & \\
\hline $\begin{array}{l}\text { Age (years): } \\
<25 \text { years }\end{array}$ & 11 & $32.4 \%$ & 1 & $6.3 \%$ & \multirow{4}{*}{$0.003 *$} \\
\hline $25-<30$ years & 11 & $32.4 \%$ & 3 & $18.8 \%$ & \\
\hline $30-<35$ years & 9 & $26.5 \%$ & 3 & $18.8 \%$ & \\
\hline$\geq 35$ years & 3 & $8.8 \%$ & 9 & $56.3 \%$ & \\
\hline \multicolumn{5}{|l|}{ Sex: } & \multirow{3}{*}{$0.960^{\text {ns }}$} \\
\hline Male & 13 & $38.2 \%$ & 6 & $37.5 \%$ & \\
\hline Female & 21 & $61.8 \%$ & 10 & $62.5 \%$ & \\
\hline \multicolumn{5}{|l|}{ Disease duration (years): } & \multirow{4}{*}{$0.037 *$} \\
\hline$<5$ years & 12 & $35.3 \%$ & 1 & $6.3 \%$ & \\
\hline $5-<10$ years & 12 & $35.3 \%$ & 5 & $31.1 \%$ & \\
\hline$\geq 10$ years & 10 & $29.4 \%$ & 10 & $62.5 \%$ & \\
\hline \multicolumn{5}{|l|}{ DAS28 score: } & \multirow{5}{*}{$0.007 *$} \\
\hline Remission $(<2.6)$ & 12 & $35.3 \%$ & 1 & $6.3 \%$ & \\
\hline Mild (2.6 - <3.2) & 7 & $20.6 \%$ & 1 & $6.3 \%$ & \\
\hline Moderate $(3.2-5.1)$ & 2 & $5.9 \%$ & 6 & $37.5 \%$ & \\
\hline Sever $(>5.1)$ & 13 & $38.2 \%$ & 8 & $50 \%$ & \\
\hline \multicolumn{5}{|l|}{ BMI: } & \multirow{4}{*}{$0.009 *$} \\
\hline Normal weight (18.5-24.9) & 9 & $26.5 \%$ & 1 & $6.3 \%$ & \\
\hline Over weight (25-29.9) & 15 & $44.1 \%$ & 3 & $18.8 \%$ & \\
\hline Obesity $(>40)$ & 10 & $29.4 \%$ & 12 & $75 \%$ & \\
\hline \multirow{3}{*}{$\begin{array}{l}\text { Hand X-rays: } \\
\text { Normal } \\
\text { Abnormal }\end{array}$} & & & & & \multirow{3}{*}{$0.052^{\mathrm{ns}}$} \\
\hline & 2 & $5.9 \%$ & 4 & $25 \%$ & \\
\hline & 32 & $94.1 \%$ & 12 & $75 \%$ & \\
\hline
\end{tabular}

Chi-square test used

Table (4) showed that there was statistically significant relation between age and ultrasound findings $(\mathrm{p}<0.05)$. There was non-significant relation between gender and ultrasound findings. There was a statistically significant relation between disease duration and ultrasound findings $(\mathrm{p}<0.05)$. There was a statistically significant relation between disease severity (DAS28) score and ultrasound findings $(\mathrm{p}<0.05)$. There was a statistically significant relation between BMI and ultrasound findings ( $p<0.05)$. There was nonsignificant relation between hand X-ray and ultrasound findings $(p>0.05)$

\section{DISCUSSION}

As regard description of age \& sex, they were 31 females (62\%) and 19 males (38\%), their ages ranged from 20 to 65 years old with a mean age of $46.3 \pm 8.4$ years.

The disease duration ranged from one year to 15 years with a mean of $6.2 \pm 1.9$ years. $26 \%$ of patients had disease duration of $<5$ years, $34 \%$ of patients had disease duration of 5-10 years and $40 \%$ of patients had disease duration of $\geq 10$ years. The BMI was $19.5 \pm 42$ $\mathrm{kg} / \mathrm{m}^{2}$. Mean of disease activity evaluated by the disease activity score in 28 joints was $4.7 \pm 1.5$.
As regards, laboratory assessment, $80 \%$ of patients had elevated ESR ( $>20 \mathrm{~mm} / \mathrm{h}$ ), $60 \%$ of patients had positive C.R.P and $92 \%$ of patients were seropositive RF.

Our study showed that the prevalence of subclinical enthesitis in patients with rheumatoid arthritis was $32 \%$. The most frequent US abnormality in RA patients were achilles enthesis in 5 patients (31.3\%) followed by quadriceps enthesis in 3 patients $(18.8 \%)$, proximal patellar enthesis in 3 patients $(18.8 \%)$, distal patellar enthesis in 3 patients $(18.8 \%)$ \& 2 patients $(12.5 \%)$ with Plantar aponeurosis enthesis.

The results of current study are supported by Hassan et al. ${ }^{(10)}$ in which 20 patients diagnosed as rheumatoid arthritis were evaluated. The mean value of ESR (first hour) was $57.9 \pm 20.6 \mathrm{~mm} / \mathrm{h} .15(75 \%)$ had positive rheumatoid factor. 15 (75\%) were CRP positive. Disease duration was less than 2 years. Ultrasound evaluation of enthesis was performed for structure, thickness, erosions, calcifications, bursitis and power Doppler signal (according to MASEI). They found that patients with rheumatoid arthritis had a significant prevalence of US enthesopathy 33.3\% (number of abnormal enthesis/total enthesis examined was $80 / 240)$. 
Gutierrez et al. ${ }^{(11)}$ provided evidence about the high prevalence of subclinical ankle involvement in patients with established rheumatoid arthritis. A statistically significant difference was found between RA patients and healthy controls in terms of PD (p < 0.001 ). No statistically significant correlation between the US findings and age, disease duration, BMI, DAS28 and laboratory data was found. In particular, we did not find a correlation between both, global and stratified US findings and RF. The results of current study are supported by Șerban et al. ${ }^{(\mathbf{1 2})}$ who reported that 35 heels in 35 patients were evaluated, $85.7 \%$ were females and mean age was $59.2 \pm 11.25$ years old. Mean BMI was $26.5 \pm 5.65 \mathrm{~kg} / \mathrm{m}^{2}$ with median disease duration of 36 years and mean DAS28-CRP $3.5 \pm 1.35$. The US examination was performed by two sonographers (with 5 and 20-years of experience in musculoskeletal US), in the same day, blinded for each other's results, and images for each assessed structure were stored. The disagreements between the two examiners were resolved by a third examiner with more than 15-years of experience in musculoskeletal US. US identified Achille's tendon enthesopathy in $11 / 35$ cases $(31.5 \%)$.

There is a statistically significant relation between disease severity (DAS28) score and ultrasound findings ( $p<0.05)$. Ali et al. ${ }^{(13)}$ performed a longitudinal study in order to investigate the correlation between US enthesitis and RA. This study included 30 adult patients fulfilling 2010 rheumatoid arthritis classification criteria. Mean age of patients was 43 years, 28 were females $(93.3 \%)$ and only 2 patients were males $(6.7 \%)$, duration of symptoms was 7 years, with SD 4.3, and ranged from 2 to 20 years. $80 \%$ of patients had positive RF. They found that DAS was always positive and highly significantly correlated to disease severity by both total US gray scale count and total US Power Doppler count. Schäfer et al. ${ }^{(14)}$ investigated 102 patients with RA and 50 patients without rheumatological disease. Both elbow joints were examined by ultrasound for hypervascularization and enthesitis. Disease Activity Score in 28 joints (DAS28), and visual analogue scale for pain (VASp) were recorded. The Rheumatoid arthritis cohort showed a significant correlation between DAS28 and ultrasound detected enthesitis $(\mathrm{p}=0.022)$.

There is a statistically significant relation between disease duration and ultrasound findings $(\mathrm{p}<0.05)$. The results of current study are supported by Belghali $\boldsymbol{e t}$ al. (15) in a single centre cross-sectional study assessed 50 patients with rheumatoid arthritis to determine the factors associated with US findings. $80 \%$ were females and mean age was $51.3 \pm 15$ years old. Mean BMI was $26.5 \pm 5.65 \mathrm{~kg} / \mathrm{m}^{2}$ with median disease duration of $5.5 \pm$ 7.3 years and mean DAS28-CRP $4.4 \pm 1.5$. This study found correlation between an evolution duration superior to 10 years and the ultrasound findings. In contrast with our results, Naredo et al. (16) studied ninety-four consecutive patients with RA. All patients underwent a US examination. 20 patients were males and 74 patients were females. Mean age was $57.6 \pm 14.3$ years (range 23-88) and mean disease duration was 69.3 \pm 58.2 months (range 5-280). Rheumatoid factor was positive in 73/94 (78\%) patients. This study showed a significant correlation between ultra-sonographic joint count for power Doppler signals with DAS and patient's overall assessment score. There was a high correlation between US parameters and CRP levels $(\mathrm{p}=0.01)$. They demonstrated that US variables did not correlate with disease duration $(\mathrm{p}=0.05)^{\left({ }^{(16)}\right.}$. The difference between our results and that of Naredo et al. can be explained by long duration of disease in our study compared to their study.

Our findings showed a statistically significant relation between BMI and ultrasound findings $(\mathrm{p}<$ $0.05)$.

Michelsen et al. ${ }^{\left({ }^{17}\right)}$ in their study evaluated 282 Achilles tendons in 141 patients with PsA. Mean age was $52.4 \pm 10.2$ years, disease duration $9.5 \pm 6.6$ years and $50.4 \%$ were females. US verified inflammatory activity in $46(16.3 \%)$ and structural damage in 148 (52.5\%) of the Achilles. Subclinical inflammation was found in $31(11 \%)$ of the Achilles insertions. None of the clinical characteristics were associated with inflammatory activity. Age, body mass index (BMI), regular physical exercise and current use of biological disease-modifying antirheumatic drugs (bDMARDs) were associated with structural damage. They showed that mean BMI was similar between patients with versus without US inflammatory activity $(\mathrm{P}=0.64)$ but significantly higher in patients with versus without US structural damage $\left(28.9 \pm 4.4 \mathrm{~kg} / \mathrm{m}^{2}\right.$ vs $27.7 \pm 4.2 \mathrm{~kg} / \mathrm{m}^{2}$, $\mathrm{p}=0.02)$. Their results match with ours and this means that structural damage of Achilles may be related not only to previous inflammation, but also to factors such as traumatic injuries, degeneration and even metabolic disorders.

Our study results showed that there is statistically significant relation between age and ultrasound findings (p. value $<0.05$ ). Our data are in accordance with those of Ibrahim et al. ${ }^{(18)}$ who studied 23 parients with RA, 10 of them were male, and 13 were female, mean age was 62.6 years, mean duration of disease was 12.6 years and mean CRP was $8.9 \mathrm{mg} / \mathrm{dL}$. This study observed significant relation between age and ultrasound findings. Given that degenerative changes, represented by enthesophytes, in articular and juxta-articular structures are likely to increase with age. This may explain the significant differences.

\section{CONCLUSION}

A significant enthesopathy was found in patients presented with RA and had no clinical manifestations of Enthesitis. US is more sensitive than physical examination in detecting enthesitis in patients with RA and can detect both inflammatory and structural lesions. A significant correlation was found between 
ultrasonographic findings and disease activity that indicates the potential importance of US in monitoring disease activity as a reliable noninvasive method. BMI, old age and long disease duration were suggested as the risk factors for subclinical enthesitis.

\section{REFERENCES}

1. Adams J, Burridge J, Mullee M et al. (2004): Correlation between upper limb functional ability and structural hand impairment in an early rheumatoid population. Clinical Rehabilitation, 18: 405-413.

2. Boutry N, Morel M, Flipo R et al. (2007): Early RA: a review of MRI and sonographic findings. American Journal of Roentgenology, 189: 1502-1509.

3. Apostolakos J, Durant T, Dwyer C et al. (2014): The enthesis: a review of the tendon-to-bone insertion. Muscles Ligaments Tendons J., 4: 333-342.

4. Rowbotham E (2011): Rheumatoid arthritis: ultrasound versus MRI. AJR., 197 : 541-546.

5. Issar P, Nadiger V, Hiran $S$ et al. (2016): Ultrasound and magnetic resonance imaging correlation of the wrist and metacarpophalangeal joints in fifty consecutive patients of rheumatoid arthritis. Indian Journal of Rheumatology, 4: 186-191.

6. Szkudlarek M, Klarlund M, Narvestad E et al. (2006): Ultrasonography of the metacarpophalan-geal and proximal interphalangeal joints in Rheumatoid Arthritis: a comparison with magnetic resonance imaging, conventional radiography and clinical examination. Arthritis Research and Therapy, 8 (2): 52-62.

7. Rosenbaum J (2015): Uveitis in spondyloarthritis including psoriatic arthritis, ankylosing spondylitis, and inflammatory bowel disease. Clin Rheumatol., 34: 9991002.

8. De Miguel E, Cobo T, Munoz-Fernandez S et al. (2009): Validity of enthesis ultrasound assessment in spondylarthropathy. Ann Rheum Dis., 68: 169-174.

9. Aletaha D, Neogi T, Silman A et al. (2010): Rheumatoid arthritis classification criteria: an American College of
Rheumatology/European League Against Rheumatism collaborative initiative. Arthritis Rheum., 62: 2569-81.

10. Hassan A, Darwish A, Mohamed F, Ibrahimb M, Abd El-Karim A (2014): Value of musculoskeletal ultrasonography in the diagnosis of peripheral enthesopathy in early spondyloarthropathy. Egyptian Rheumatology \& Rehabilitation, 41: 51-57.

11. Gutierrez M, Pineda C, Salaffi F et al. (2016): Is ankle involvement underestimated in rheumatoid arthritis? Results of a multicenter ultrasound study. Clinical Rheumatology, 35: 2669-2678.

12. Serban O, Fodor D, Papp I et al. (2019): Reasons for discordances between ultrasonography and magnetic resonance imaging in the evaluation of the ankle, hindfoot and heel of the patients with rheumatoid arthritis. Med Ultrasound, 21 (4): 405-413.

13. Ali R, Daifallah O, Abozaid H et al. (2019): A longitudinal study of the 28 joints of disease activity score by ultrasonographical examination in rheumatoid arthritis patients. J Med Ultrasound, 27:33-9.

14. Schäfer V, Recker F, Vossen D et al. (2020): Prevalence of Elbow Joint Arthritis and Enthesitis in Rheumatoid Arthritis. J Clin Med., 9 (5): 1590.

15. Belghali S, El Amri N, Zaghouani H et al. (2017): Clinical and ultrasound concordance in the detection of synovitis in rheumatoid arthritis: a transversal study about 50 patientsInt. J. Clin. Rheumatol., 12 (3): 41-49.

16. Naredo E, Gamero F, Bonilla $G$ et al. (2005): Ultrasonographic assessment of inflammatory activity in rheumatoid arthritis: comparison of extended versus reduced joint evaluation. Clin Exp Rheumatol., 23: 881-4.

17. Michelsen B, Diamantopoulos A, Soldal D et al. (2017): Achilles enthesitis defined by ultrasound is not associated with clinical enthesitis in patients with psoriatic arthritis. RMD Open, 3:e000486.

18. Ibrahim $G$, Groves $C$, Chandramohan $M$ et al. (2011): Clinical and Ultrasound Examination of the Leeds Enthesitis Index in Psoriatic Arthritis and Rheumatoid Arthritis. ISRN Rheumatology, 5: 1-5. 